\title{
Akurasi Pemeriksaan HbA1c dalam Mendeteksi Gangguan Toleransi Glukosa pada Anak dan Remaja Obes dengan Riwayat Orang Tua DM Tipe 2
}

\author{
Abdi Wijaya,* Aditiawati, ${ }^{*}$ Irsan Saleh** \\ *Bagian Ilmu Kesehatan Anak, ** Bagian Farmakologi Fakultas Kedokteran Universitas Sriwijaya/RS Moh Hoesin, Palembang
}

\begin{abstract}
Latar belakang. Obesitas dengan riwayat orang tua diabetes mellitus (DM) tipe 2 berhubungan dengan gangguan toleransi glukosa, dislipidemia, dan DM. Toleransi glukosa terganggu (TGT) merupakan pertanda awal terjadinya DM tipe 2. Hemoglobin A1c (HbA1c) telah muncul menjadi alat diagnostik untuk mengidentifikasi DM dan subjek yang berisiko menderita DM. Rekomendasi ini didasarkan pada data dari orang dewasa yang menunjukkan hubungan antara HbAlc dengan terjadinya DM di kemudian hari. Penelitian yang khusus ditujukan pada populasi anak dan remaja masih sedikit.

Tujuan. Mengetahui penggunaan dan titik potong optimal pemeriksaan HbA1c dalam mendiagnosis gangguan toleransi glukosa pada anak dan remaja obesitas dengan faktor risiko dibandingkan dengan tes toleransi glukosa oral (TTGO).

Metode. Dilakukan uji diagnostik terhadap 40 anak obesitas (Indeks Massa Tubuh menurut umur dan jenis kelamin berdasarkan Z score WHO $2008 \geq+2$ SD) usia 10-15 tahun dengan riwayat orang tua DM tipe 2 tahun di Palembang dari Desember 2013 - Februari 2014. Pada semua subjek dilakukan pemeriksaan HbA1c dan TTGO.

Hasil. Ditemukan dua anak dengan TGT. Dari analisis kurva Receiver Operating Characteristic (ROC) didapatkan titik potong optimal pemeriksaan $\mathrm{HbA1}$ c adalah 5,55\% dengan nilai sensitivitas 67\% dan spesifisitas 20\%, area Under the Curve (AUC) diperoleh sebesar $79,3 \%$ (95\% IK 45,7\%-100\%).

Kesimpulan. Nilai pemeriksaan HbA1c $\geq 5,55 \%$ dianjurkan sebagai alat skrining untuk mengindentifikasi TGT pada anak dan remaja obesitas dengan faktor risiko. Sari Pediatri 2015;17(1):17-20.
\end{abstract}

Kata kunci: obesitas, riwayat orang tua, toleransi glukosa terganggu (TGT), HbA1c

\section{Accuracy in HbAlc Examination for Detecting Impaired Glucose Tolerance in Obese Children and Adolescents with History of Parents with Type 2 DM}

Abdi Wijaya, ${ }^{*}$ Aditiawati, ${ }^{*}$ Irsan Saleh**

Background. Childhood obesity with parental history of type 2 Diabetes Mellitus (DM) is associated with an increased likelihood for having impaired glucose tolerance, dyslipidemia, and DM. Hemoglobin A1c (HbA1c) has emerged as a recommended diagnostic tool for identifying type $2 \mathrm{DM}$ among subjects who are at risk for the disease. This recommendation is based on data in adults showing the relationship between HbA1c with future development of DM. However, there are lacking studies of this correlation among pediatric population.

Objective. The aim of the study was to evaluate HbA1c as a test for impaired glucose tolerance in obese children and adolescents with risk factor and identify the optimal HbA1c threshold (optimal cut of point).

Methods. We studied 40 obese children and adolescents (BMI according WHO $2008 \mathrm{Z}$ score $\geq+2$ SD for age and gender) age 10-15 years with parental history of type 2 Diabetes DM in Palembang. All subjects underwent HbA1c and oral glucose tolerance test (OGTT).

Results. Two out of 40 subjects had impaired glucose tolerance. Based on the receiver operating characteristic curve, the optimal cut point of HbA1c in relation to impaired glucose tolerance diagnosed by OGTT was $5.55 \%$, which yield sensitivity of $67 \%$ and specificity of $20 \%$, with area under the receiver operating characteristic curve of $79.3 \%$ (95\% CI 45.7\%-100\%).

Conclusions. HbA1c value of $5.55 \%$ should be used as a screening tool to identify impaired glucose tolerance in obese children and adolescents with risk factor. Sari Pediatri 2015;17(1):17-20.

Keywords: obesity, parents history, impaired glucose tolerance, HbA1c

Alamat korespondensi: Dr. Abdi Wijaya,Sp.A Bagian Kesehatan Anak, Fakultas Kedokteran, Universitas Sriwijaya, Jalan Jenderal Sudirman Km. 3,5, Palembang, Indonesia.Telepon +61-771-372832, +62-812-71372673, Fax.+62-711-376445. E-mail : abdiwijaya_93@yahoo.com 
$\mathrm{P}$ revalensi obesitas anak dan remaja telah meningkat secara dramatis. Obesitas berisiko tinggi menimbulkan gangguan metabolik, seperti diabetes mellitus (DM) tipe 2 . Semakin besar indeks massa tubuh (IMT) semakin besar risiko menderita DM tipe 2., ${ }^{1,2}$ Diabetes mellitus tipe 2 terjadi oleh dua kelainan utama, yaitu adanya defek sel beta pankreas sehingga pelepasan insulin berkurang dan adanya resistensi insulin. Gangguan toleransi glukosa merupakan tanda awal DM tipe 2. Pada fase ini, masih belum tampak gejala klinis diabetes sehingga disebut juga sebagai fase asimptomatik. ${ }^{3}$ Prevalensi gangguan toleransi glukosa anak dan remaja obesitas sekitar 30\%-40\%. ${ }^{4-6}$ Pada kenyataannya, tidak semua anak yang menderita kelebihan berat badan atau obesitas memiliki peluang untuk menderita DM tipe 2. Anak obesitas dengan orang tua diabetes memiliki peluang yang lebih besar untuk terkena DM. ${ }^{7}$ Tes toleransi glukosa oral (TTGO) dianggap sebagai baku emas untuk mendeteksi prediabetes pada individu yang berisiko menderita DM. Hemoglobin A1c direkomendasikan sebagai alat diagnostik untuk mengidentifikasi DM dan subjek yang berisiko menderita DM. Namun, rekomendasi ini didasarkan pada penelitian orang dewasa, serta belum adanya nilai standar HbA1c untuk anak dan remaja. ${ }^{8-10}$

\section{Metode}

Telah dilakukan uji diagnostik cross sectional pada siswa satu sekolah dasar (SD) dan dua sekolah menengah pertama (SMP) di Palembang dari periode Desember 2013 sampai dengan Februari 2014. Subjek penelitian dipilih dengan purposive sampling. Anak dan remaja dengan obesitas yang memenuhi kriteria inklusi adalah dengan IMT menurut umur dan jenis kelamin berdasarkan $Z$ score WHO $2008 \geq+2$ SD, memiliki riwayat orang tua dengan DM tipe 2, dan berusia 10 sampai 15 tahun. Kriteria ekslusi adalah anak sakit atau menolak pemeriksaan. Estimasi besar sampel adalah 40 subjek, dengan $\alpha=0,05$ dan power $=90 \%$. Jumlah subjek penelitian adalah 40 anak dan remaja.

Data yang dikumpulkan meliputi riwayat, pemeriksaan fisik, dan pemeriksaan laboratorium. Dilakukan anamnesis untuk mengidentifikasi karakteristik dasar subjek, termasuk nama, umur, jenis kelamin, dan alamat. Pemeriksaan fisik dilakukan untuk mengukur berat badan dan tinggi badan, hasilnya kemudian diplot pada kurva IMT menurut umur dan jenis kelamin.

Dilakukan pemeriksaan TTGO dan HbA1c kepada semua subjek penelitian. Pengambilan sampel darah dilakukan setelah puasa 8 jam, dan dimulai dengan pengambilan darah untuk pemeriksaan HbA1c (sampel pertama) dan sampel gula darah puasa (sampel kedua), kemudian subjek minum larutan glukosa $1,75 \mathrm{~g}$ per $\mathrm{kg}$ berat badan dalam $300 \mathrm{ml}$ air, maksimal $75 \mathrm{~g}$, dalam waktu 5 menit. Pengambilan sampel ketiga dilakukan pada menit ke-120 setelah minum larutan glukosa. Definisi DM tipe 2 adalah kadar glukosa puasa $\geq 126$ $\mathrm{mg} / \mathrm{dL}$ atau kadar glukosa jam kedua $\geq 200 \mathrm{mg} / \mathrm{dL}$ dan definisi gangguan toleransi glukosa adalah kadar glukosa puasa $100-125 \mathrm{mg} / \mathrm{dL}$ atau kadar glukosa jam kedua 140-199 mg/dL berdasarkan TTGO.

Pengambilan sampel darah, pengukuran $\mathrm{HbAlc}$ dan glukosa plasma dilakukan oleh petugas Laboratorium Prodia. Pengukuran $\mathrm{HbA1c}$ dilakukan dengan metode High Performance Liquid Chromatography (HPLC). Semua prosedur penelitian dijelaskan kepada semua subjek beserta orang tua dan dilakukan informed consent. Penelitian ini disetujui oleh Komite Etik fakultas kedokteran Universitas Sriwijaya, Palembang, Indonesia.

Data disajikan secara deskriptif dalam bentuk Tabel dan Grafik. Untuk menentukan kekuatan diagnostik, penghitungan dilakukan untuk mendapatkan diagram receiver operator characteristic (ROC), nilai titik potong (cut off point), area under the curve (AUC), sensitivitas, spesifisitas, nilai duga positif dan nilai duga negatif dilakukan menentukan kekuatan diagnostik. Analisis data dilakukan dengan menggunakan piranti lunak SPSS versi 16.0

\section{Hasil}

Didapatkan 40 anak dan remaja obesitas dengan riwayat orang tua diabetes mellitus tipe 2, $19(47,5 \%)$ subjek lakilaki dan $21(52,5 \%)$ perempuan. Usia rata-rata adalah 13 (kisaran 10-15) tahun. Rerata IMT adalah 32 (SD 3,41) $\mathrm{kg} / \mathrm{m}^{2}$. Karakteristik umum tertera pada Tabel 1.

Terdapat dua anak dari 40 subjek penelitian dengan toleransi glukosa terganggu $(157 \mathrm{mg} /$ dL dan $183 \mathrm{mg} / \mathrm{dL}$ ) dan 38 anak (95\%) dengan toleransi glukosa normal. Tidak ditemukan anak dengan DM tipe 2. Di antara 40 subjek peneliti- 
an, $34(85,0 \%)$ dengan hasil pemeriksaan HbA1c $<5,7 \%$, lima dengan hasil pemeriksaan HbAlc $5,7 \%-6,4 \%$, dan satu dengan hasil pemeriksaan $\mathrm{HbA} 1 \mathrm{c}>6,4 \%$.

Tabel 1. Karakteristik umum $(\mathrm{n}=40)$

\begin{tabular}{lcc}
\hline Karakteristik subjek & $\mathrm{n}$ (orang) & Persentase \\
\hline Jenis kelamin & & \\
$\quad$ Laki-laki & 19 & 47,5 \\
$\quad$ Perempuan & 21 & 52,5 \\
Kelompok usia (tahun) & & \\
10-12 & 10 & 25 \\
13-15 & 30 & 75 \\
Pendidikan & & \\
SD & 1 & 2,5 \\
SMP & 39 & 97,5 \\
\hline
\end{tabular}

Berdasarkan kurva ROC, titik potong optimal dari $\mathrm{HbA1c}$ untuk mendeteksi gangguan toleransi glukosa dibandingkan TTGO adalah 5,55\%, dengan sensitivitas $67 \%$ dan spesifisitas $20 \%$, nilai duga positif $83 \%$, dan nilai duga negatif $3,57 \%$, dengan nilai AUC 0,793 (95\% CI 457-1), $\mathrm{p}<0,095$ (Gambar 1).

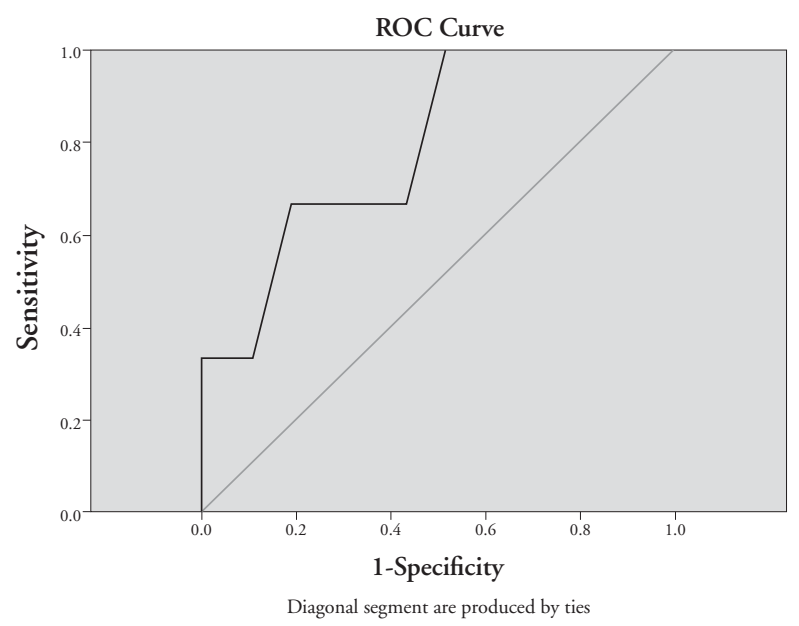

Gambar 1. Kurva Receiver Operating characteristic (ROC) pemeriksaan HbA1c dalam mendeteksi TGT dibandingkan dengan TTGO.

\section{Pembahasan}

Tes toleransi glukosa oral (TTGO) dianggap sebagai baku emas untuk mendeteksi prediabetes pada individu yang berisiko menderita DM. Namun, TTGO memerlukan fase puasa sebelum pemeriksaannya dan juga diperlukan dua kali pengambilan darah. Bagi anak dan remaja, hal tersebut sangat menganggu dan menyebabkan keengganan untuk melakukan pemeriksaan ini. Sebaliknya, HbA1c tidak memerlukan keadaan puasa dalam pemeriksaannya, menggambarkan keadaan glukosa darah dalam jangka waktu yang lebih lama (2-3 bulan), tidak dipengaruhi perubahan gaya hidup jangka pendek, serta merupakan prediktor yang baik terhadap komplikasi yang berhubungan dengan DM. ${ }^{11}$

Kami mendapatkan dua dari 40 subjek penelitian dengan toleransi glukosa terganggu (TGT). Hal tersebut berbeda dengan penelitian lainnya. Lee $\mathrm{dkk}^{12}$ menemukan $27 \%$ anak memiliki gangguan toleransi glukosa dan Ginting ${ }^{13}$ menemukan 27,5\% anak dengan gangguan toleransi glukosa terganggu.

Kami juga mendapatkan $34(85,0 \%)$ anak dengan kadar HbAlc < $5,7 \%$, lima (12,56\%) HbAlc 5,7-6,4\%, dan satu $(2,5 \%)$ HbAlc $>6,4 \%$. Sementara itu, Nowicka $\mathrm{dkk}^{14}$ melaporkan temuan yang berbeda, yaitu $77 \%$ anak dengan kadar HbA1c <5,7\%, 21\% HbA1c 5,7\%-6,4\%, dan $1 \%$ HbAlc $>6,4 \%$. Namun, hasil tersebut sejalan dengan penelitian Ginting yang mendapatkan $87,5 \%$ anak dengan kadar $\mathrm{HbAlc}<5,7 \%, 11,6 \% \mathrm{HbA1c} 5,7 \%$ $6,4 \%$, dan $1,4 \%$ HbAlc $>6,4 \% .^{13}$

Titik potong optimal nilai HbA1c untuk mendeteksi gangguan toleransi glukosa adalah 5,55\%, dengan sensitivitas $67 \%$, dan spesifisitas $20 \%$. Lee $\mathrm{dkk}^{12}$ melaporkan bahwa titik potong optimal dari HbA1c adalah 5,8\%, dengan sensitivitas $64,7 \%$, dan spesifisitas $61,6 \%$. Nowicka $\mathrm{dkk}^{14}$ melaporkan titik potong optimal $\mathrm{HbA1}$ c adalah $5,8 \%$ dengan sensitivitas $67,7 \%$, dan spesifisitas $87,6 \%$. Sementara itu, Ginting ${ }^{13}$ melaporkan titik potong nilai $\mathrm{HbA1c}$ adalah 5,25\% ,dengan sensitivitas 63\%, dan spesifisitas 64\%.

Berdasarkan pada penelitian orang dewasa, American Diabetes Associtation (ADA) merekomendasikan ketegori nilai $\mathrm{HbA1c}$ pada individu berisiko menjadi diabetes jika nilai HbA1c adalah 5,7\%-6,4\%. Namun, nilai batas bawah 5,7\% untuk pemeriksaan HbA1c seperti yang direkomendasikan ADA ini mungkin kurang tepat untuk diterapkan untuk populasi anak dan remaja obesitas dengan riwayat orang tua DM tipe 2. Berdasarkan hasil penelitian ini didapatkan titik potong yang lebih rendah, yaitu 5,55\% dan didukung pula dari penelitian lain yang juga mendapatkan titik potong yang lebih rendah daripada rekomendasi ADA. ${ }^{11}$ 


\section{Kesimpulan}

Obesitas dengan riwayat orang tua diabetes mellitus tipe 2 tidak terkait dengan peningkatan risiko gangguan toleransi glukosa. Nilai HbA1c 5,55\% dapat digunakan sebagai alat skrining untuk mengidentifikasi anak dan remaja dengan gangguan toleransi glukosa. Ketidakterkaitan hasil penelitian ini antara anak dan remaja obesitas yang memiliki riwayat orang tua DM tipe 2 dengan gangguan toleransi glukosa dapat disebabkan oleh jumlah sampel yang masih terlalu kecil.

\section{Daftar pustaka}

1. Calle E, Thun MJ, Petrelli JM, Rodriguez C, Heath CW. Body mass index and mortality in a prospective cohort of US adults. N Engl J Med 1999; 341:1097-105.

2. Giugliano R, Carneiro EC. Factor associated with obesity in school children. J Pediatr 2004;80: 17-22.

3. Lillioja S, Morr DM, Howard BV. Impaired glucose tolerance as a disorder of insulin action. $\mathrm{N}$ Engl J Med. 1988;318:1217-25.

4. Holtz C, Smith TM, Winters FD. Childhood obesity. J Am Osteopath assoc 1999;99:366-71.

5. Sinha R, Fisch G, Teague B, Tamborlane W, Banyas B, Allen K, dkk. Prevalence of impaired glucose tolerance among children and adolescents with marked obesity. NEJM 2002;346:802-10.

6. Weiss R, Cali A, Caprio S. Pathogenesis of insulin resistance and glucose intolerance in childhood obesity.
In: Freemark M, editor. Pediatric obesity: etiology, pathogenesis, and treatment. New York: Humana Press - Springer Science \& Business Media; 2010.h. 234-42.

7. Gong L. kao WHL. Brancati FL. Turner MB. Gary TL. Association between parental history of type 2 diabetes and glycemic control in urban African American. Diabetes Care 2008;31:1773-6.

8. Rohlfing C, Little R, Wiedmeyer H, England J, Madsen R, Harris M, dkk. Use of GHb (HbAlc) in screening for undiagnosed diabetes in the U.S. population. Diabetes Care 2000;23:187-91.

9. Edelman D, Olsen MK, Dudley TK, Harris AC, Oddone EZ. Utility of hemoglobin A1c in predicting diabetes risk. J Gen Intern Med 2004;19:1175-80.

10. Pradhan AD, Rifai N, Buring JE, Ridker PM. Hemoglobin A1c predicts diabetes but not cardiovascular disease in nondiabetic women. Am J Med 2007;120:72-7.

11. American Diabetes Association. Diagnosis and classification of diabetes mellitus. Diabetes Care 2010; 33(Suppl. 1): S62-9.

12. Lee HS, Park HK, Hwang JS. HbA1c and Glucose intolerance in obese children and adolescents. Diabet Med 2012;129:102-5.

13. Ginting E. Uji diagnostik hemoglobin A1c dalam mendeteksi gangguan toleransi glukosa pada anak dan remaja obes di Palembang. (tesis). Palembang: Fakultas Kedokteran Universitas Sriwijaya, 2013.

14. Nowicka P, Santoro N, Liu H, Lartaud D, Shaw M, Goldberg R, dkk. Utility of hemoglobin A1c for diagnosing prediabetes and diabetes in obese children and adolescents. Diabetes Care 2011;34:1306-11. 